\title{
6
}

\section{TRANSFORMING CLASSROOM DISCOURSE AS A RESOURCE FOR LEARNING}

\section{Adapting interactional ethnography for teaching and learning}

\section{W. Douglas Baker}

\section{Summary}

This chapter shows how an interdisciplinary team of instructors (a professor of literature and a professor of English education) transformed classroom talk from a graduate class into a resource for constructing interpretive principles and practices of literary texts and generated deeper learning opportunities for the students, most of them practicing classroom teachers. By integrating an Interactional Ethnographic perspective, the instructors examined selected classroom discourse and engaged students in reflexive processes to explore classroom interactions and recognize how the experiences may lead them to (re)think and expand repertoires for interpreting and teaching literature.

\section{Introduction}

For instructors teaching higher education or secondary school students how to interpret literary texts, one of the challenges is making visible to students interpretative principles and practices through discursive strategies (i.e., "the spoken words that...teachers [use] during classroom conversations to explore critical issues related to teaching (Rex \& Schiller, 2009)," cited in Vetter, Schieble, \& Meacham, 2018, p. 256). By "practices" and discursive strategies I refer to actions situated within particular sociocultural contexts that become norms for a group (e.g., students and teachers in classrooms) and shape and are shaped by the group's discourse (Bloome, Carter, Christian, Otto, \& Shuart-Faris, 2005; Gee \& Green, 1998; Street, 2016). Teachers of literature have no agreed upon set of interpretative principles or practices, yet they construct with students over time what counts as interpretation and learning (cf. Olsen, 2018). For example, some instructors who focus on training teachers of literature as preparation for language arts instruction incorporate the metaphor of "lenses," ostensibly reflecting 
literary theories intended to encourage students to recognize particular interpretative assumptions and practices (e.g., a "feminist lens") (Appleman, 2009; Wilson, 2014).

Teachers' disciplinary understandings, experiences and pedagogical knowledge shape classroom practices and learning opportunities (Carney \& Indrisano, 2013), especially because teachers often teach how they were taught (Marshall \& Smith, 1997). Therefore, teachers' experiences with literary texts, including classroom discourse, inform how students learn to interpret literature and how they recognize and acknowledge interpretative norms. For example, during my undergraduate literature courses, professors drew on New Criticism, an interpretative tradition focused explicitly on the text, not situated within cultural, political, or authorial contexts (cf. Francis, 2008). Consequently, as a high school teacher, I focused on New Critic principles and introduced students to other theories only as I experienced them later.

Elisabeth Däumer, a colleague and a professor of literature, and I, a professor of English education, began to explore through interdisciplinary conversations how teachers learn to interpret texts and the apparent consequences of their experiences for their students, and how teachers might learn to build on experiences to deepen their knowledge and repertoires. Although we are situated within the Department of English Language and Literature and we prepare teachers, we do so in courses centered on our disciplines. Elisabeth provides opportunities for students to read literary texts and explore interpretive traditions; I guide students to design literature curricula for students. In part because of disciplinary backgrounds, we discovered limits to how certain we could be about selected phenomena of each other's area of expertise, especially when concepts appeared similar (Baker \& Green, 2007). For example, based on our disciplinary traditions we defined "theory" and "critical theory" differently; we debated the use of "lenses" as a metaphorical, interpretative tool; and what constituted research for each of us differed. For Elisabeth, closely reading literary texts, constructing, and representing arguments supported by interpretative principles and cultural perspectives reflected her inquiry approach; for me, adapting an ethnographic perspective and analyzing classroom discourse were features of my research - and integral to my teaching. However, we learned our disciplinary differences could become resources for learning, for us and for our students (Baker \& Däumer, 2015a).

Our conversations led us to create an interdisciplinary, team-taught graduate course to examine literary texts with practicing teachers (who were seeking a graduate degree) and to explore how the experiences influenced their knowledge of interpretative principles and practices and, consequently, how they communicate principles and practices to their students. The logic of our inquiry, and increasing reflexivity of the process, had consequences for how we (re)designed the course and for deeper learning opportunities we afforded the teachers, including how they enhanced their communicative competence of describing interpretative approaches to literary texts. By adapting an ethnographic perspective 
(Green \& Bloome, 1997) of classroom discourse and discursive strategies, we observed how we constructed interpretative principles and practices with students and how the interactions between us modeled interdisciplinary conversations as resources for students' deeper learning.

\section{Focus of the chapter}

For teachers of literature, classroom interactions ostensibly lead to interpretations of texts; however, the conversations typically rely on participants' memory of texts read before class, or of previous discussions and interpretative approaches. Since we planned to work with graduate students, I suggested we record classroom talk, transcribe, examine and archive interactions throughout the semester; therefore, we would not rely on memory. As I will show, the records of classroom talk led us to better understand what we were collectively accomplishing. I recorded classroom talk and transcribed it into written text, which provided a record of the interactions and allowed me to map events of a class meeting. An event is conceptually linked with social practices, emphasizing what is accomplished through discursive interactions (Bloome et al., 2005; Green \& Meyer, 1991). In other words, transcripts provided physical texts as a resource to Elisabeth and me for deepening our understanding of selected classroom interactions and for students to observe, acknowledge, and recognize significance connections among texts, or intertextual links (Bloome et al., 2005), and for what they were learning (cf. McCann, 2014).

As I will show, transforming selected classroom discourse into written texts allowed us to observe how we were constructing discipline-based principles of interpreting literary texts with the students. Further, I describe how, by adapting an Interactional Ethnographic perspective (Castanheira, Crawford, Dixon, \& Green, 2001), we created a metadiscourse for us to develop ways of talking or negotiating interdisciplinary discussions and understandings (Baker \& Däumer, 2015b). An Interactional Ethnographic perspective uses principles of ethnography to examine discursive interactions (e.g., seeking an "insider's" point of view, triangulating evidence to support claims, and engaging in abductive thinking); therefore, for example, we strived to understand students' perspectives through analysis of their discourse. By metadiscourse, I refer to "how we use language out of consideration for our readers or hearers based on our estimation of how best we can help them process and comprehend what we are saying" (Hyland, 2017, p. 17; cf. Tang, 2017). Elisabeth and I sought to make visible links among our disciplinary discourses, personal experiences, and shared classroom practices; the language and principles of Interactional Ethnography (IE) assisted us in our efforts.

Our goals for the course included guiding students to enhance their communicative competence as teachers of literary texts. That is, we provided students with learning opportunities to reflect on past literary practices, examine classroom interpretative events, and become more reflexive as readers and as teachers 
of literary texts. In the process, as I will show, students deepened their understanding of how literary principles and practices are constructed through discursive strategies and engaged others (i.e., their peers and students) in demonstrating linguistic and discursive knowledge (Gumperz, 1997; Hymes, 1972), especially in terms of interpreting literature (Blau, 2014).

In particular, I address the following questions:

- How might observing, analyzing, and tracing discursive interactions guide teachers to engage with students as inquirers in order to provide opportunities for deeper learning and to enhance teachers' and students' capacity to develop communicative competence as interpreters of literary texts?

- How might interdisciplinary conversations between teachers, especially ones based on analysis of classroom discourse, lead to deeper understanding of classroom interactions and disciplinary perspectives for teachers and their students?

\section{The course: An interdisciplinary approach to shaping opportunities for learning}

As an interdisciplinary team, Elisabeth and I designed the graduate course, "Reading, Interpreting, and Responding to Literary Texts," for practicing teachers interested in teaching literature and earning a Master's degree. The 15-week class met once a week for 3 hours, and most of the 13 students (nine of them) were secondary school teachers (grades 6-12). Since we would be interacting across grade levels and disciplines, we recognized the need to develop a shared language, a metadiscourse, particularly because classroom language shapes and is shaped by teacher and students' interactions over time; in turn, the interactions expand "the concept of meaning in context to explore how within and across the face-to-face and moment-by-moment interactions, teachers and students construct a language of the classroom" (Rex \& Green, 2008, p. 575).

The metadiscourse would serve as a language to help us observe disciplinary perspectives and differences and to infer theoretical assumptions when interpreting literary texts (e.g., raising a series of questions, such as, what counts as an interpretation to a particular group or person?). Central to this perspective is our understanding of disciplines, as well as classrooms, as languacultures (Agar, 1994; Baker \& Däumer, 2015a), which refers to how members of a group interweave cultural assumptions or norms and language in particular contexts, or "languagein-use." Languaculture, coined by anthropologist Michael Agar (1994), implies that a language and culture cannot be separated; language is imbued with culture, a conceptual system constantly being constructed. From this perspective, members of a social group interact and generate local norms through discursive strategies, particularly for recognizing what counts to the group as knowledge. Thus, through social and literate practices over time, participants negotiate what phenomena are important, how knowledge of objects or concepts or intertextual 
links are constructed, defined, recognized, acknowledged, and interactionally accomplished as significant to members (Bloome et al., 2005, pp. 40-41).

Of course, between groups there will be moments of misunderstanding or confusion. Here, Agar (1994) provides another useful concept, "rich points," or "moments when something happens [between people of different cultures] and participants suddenly 'don't know what's going on' between them," or are confused (p. 106). So, if disciplines and classrooms can be viewed as languacultures, members of different disciplines or classrooms may be confused at times during interactional moments, generating potential "rich points," which may be ignored or examined. However, even within a classroom, teachers and students may observe rich points, particularly since teachers and students may, of course, have very different understandings of phenomena, and the rich points may become resources for participants to acknowledge and discuss and build deeper understandings of a phenomenon.

For example, during the first 2 weeks of the course one of the students, Denise, described in a reflective essay contextual factors she required when she was younger to become engaged as a reader: freedom to choose texts on topics of interest, adult readers as models, and authentic experiences for reading. However, during the first class meetings, she admonished her secondary school students for their lack of motivation as readers, their occasional attendance, and apparent disrespect for her. Elisabeth and I, after analyzing her written assignment and classroom talk, observed a "rich point" between Denise and her students: Denise acknowledged her needs as a younger reader for particular contexts; yet, she had not offered her students similar opportunities. That apparent disconnect would prove worth exploring, as I describe later.

Recording and transforming verbal text to a transcript, proved vital to recognizing potential rich points, particularly since classroom conversations occur moment-by-moment in "real" time and may be difficult to recall in detail. Therefore, our decision to analyze classroom discourse provided the students and us with opportunities to (re)examine interactions, (re)design curricula, and enhance our collective reflexivity (cf. Rex \& Schiller, 2009). More specifically, recording, transcribing, and analyzing discursive interactions in the classroom provided resources to deepen students' learning, and ours, often reshaping what we thought we understood. Interactional Ethnography (IE) became integral to our instruction and how we observed referential links, developed evidence for analytic claims, and (re)designed curricula based on new information or patterns uncovered.

\section{Adapting an interactional ethnographic perspective}

Ethnography can be viewed as epistemology, a way of coming to understand phenomena (Anderson-Levitt, 2006), guiding a (teacher) researcher to develop a "logic-in-use," one reliant on particular principles of operation (Green, Skukauskaite, \& Baker, 2012). IE recognizes classroom discourse as a basis for discursive interactions and for understanding what counts to members of a classroom 
as local, social, and literate practices and disciplinary knowledge (Kelly, Luke, \& Green, 2008). Adapting an Interactional Ethnographic perspective for observing and analyzing classroom interactions led us to engage in principled actions similar to those of ethnographers of education, who are often external to classrooms and other educational settings (Bloome, Castanheira, Leung, \& Rowsell, 2018): describing what we observed; avoiding evaluation in the moment - a challenge because teachers are always assessing students' responses; raising questions to clarify what we think we observed or heard; and gathering multiple perspectives or iterations of observations to support claims we made.

Through my earlier research in an intergenerational (grades 9-12) studio art class (Baker, 2001; Baker, Green, \& Skukauskaite, 2008), I recognized the potential of using principles and language of ethnography to observe and listen to a teacher and students, as I strived to get close to an "insider's" perspective of the class, particularly for understanding what constituted being an artist in the class. Therefore, I described in fieldnotes what I observed, video recorded class sessions, transcribed selected days, and analyzed sequences. This approach helped me demonstrate my intentions to the teacher and students, particularly dissuading me from evaluating or making assumptions about the class or studio art without triangulating evidence, and revealing limitations to what I could claim (Baker \& Green, 2007). The Interactional Ethnographic perspective, which draws on theories of communicative competence, sociolinguistics, and anthropology (Castanheira et al., 2001), therefore, guided and led me to similarly record interactions for the graduate course.

Because of my experience with IE, I acted as "cultural guide" for Elisabeth, describing methodological assumptions and principles and showing how discourse of ethnography provided a common language, or a metadiscourse, for observing classroom interactions and constructing shared or common knowledge for the class (cf. Edwards \& Mercer, 1987). Furthermore, our agreement provided space to dialogically explore discourse from each other's discipline; that is, we inquired and sought to understand more from the other person's perspective, not impose our assumptions about what we thought we observed or heard. Moreover, we avoided monologic or authoritative perspectives (Hunt, 2018), including our privileged positions as instructors. Instead, we questioned authoritative perspectives of our fields to build shared expertise with each other and with the students. Although these agreements aligned well with our plans for the course, they proved challenging.

\section{Analytical sequence: Recording and transcribing classroom discourse}

With permission of the students, I audio recorded each class session and wrote fieldnotes (when I was not leading discussion). Each class period began with a printed agenda, including a list of assigned readings (students were to have read). Class meetings typically included a guest speaker for the first 60 minutes 
(many of them were colleagues from the literature or English education programs, or alumni who were secondary school teachers). Next, a student would lead us through a "reading event," comprised of the student selecting and reading a text, providing context for its selection, and initiating a discussion about it. Generally, the third hour was devoted to students' projects and discussion of assigned readings.

After each meeting, I transcribed most of the classroom talk before the next class session, creating a "running record" of the discourse and interactions, and this process represented a first layer of analysis. Next, from the running record, I generated an "event map," a list of the actual, sequenced activities, bounded and named according to topic; and I listed clock and recorded time. Finally, I added relevant information from fieldnotes (or "headnotes"). These three analytical practices provided an initial transcript and map of classroom events, creating opportunities for microanalysis of selected interactions. In the next section, I describe how an interpretative principle was constructed through engaging in classroom conversations, analyzing selected sequences of discourse, and acknowledging thematic connections of the discourse across multiple classroom events and meetings.

\section{Classroom participants as inquirers: Using transcripts to trace the construction of interpretative principles and practices}

One course goal, stated in the syllabus, was to "construct, engage in, and reflect on research-based practices over the semester." We expected students to engage in recursive processes: read assigned texts, examine suggested research-based practices of various scholars, and explore and develop interpretative principles and practices. But we avoided simply providing students with answers; rather, we encouraged students to become inquirers and seek answers. Tracing connected events requires teachers or researchers to observe how participants of a class recognize and acknowledge an event or concept as significant. Next, I describe two examples of tracing concepts tied by discourse and different classroom events.

\section{Example 1}

On January 30 (third class meeting), Elisabeth and I initiated a series of classroom activities and discussions about how readers draw on experiences to interpret texts. We began with Mellor, Patterson, and O'Neill (2000), who suggest readers fill "gaps" of literary texts based on readers' cultural norms and experiences (e.g., gender). During the next class (February 6) we read a poem and another short text to further discuss how readers fill gaps based on tone, diction, and context. Then, on February 13, we discussed Prince Cinders by Babette Cole, a children's picture book that reverses the gender of the traditional story of Cinderella. Prior to reading Prince Cinders, I suggested to the class to adapt a "feminist" approach 
TABLE 6.1 Classroom interaction on using literary lenses (February 13)

\begin{tabular}{|c|c|c|c|}
\hline Speaker & Line & Discourse & Notes \\
\hline \multirow[t]{12}{*}{ Elisabeth } & 101 & You know this idea Doug & \multirow[t]{3}{*}{ i.e., literary "lens" } \\
\hline & 102 & "knowing a lens" is a little artificial actually & \\
\hline & 103 & you know & \\
\hline & 104 & It's really just something to teach theory & \multirow[t]{4}{*}{ literary theory } \\
\hline & 105 & It's not really & \\
\hline & 106 & how individual theorists necessarily & \\
\hline & 107 & interact with texts & \\
\hline & 108 & Most people use like a kaleidoscope & different metaphor \\
\hline & 109 & You know do different things at the same time & $\begin{array}{l}\text { i.e., bring theories } \\
\text { together }\end{array}$ \\
\hline & 110 & I always use psychoanalysis and gender & Example \\
\hline & 111 & $\begin{array}{l}\text { and sometimes the texts themselves seem to } \\
\text { invite particular approaches more than others }\end{array}$ & \\
\hline & 112 & Still a very useful way to start & i.e., "lenses" \\
\hline \multirow{4}{*}{ Maya } & 113 & It seems kind of like what um & \\
\hline & 114 & Dr. Blau was saying about & \multirow{2}{*}{ earlier in the class } \\
\hline & 115 & [pause] & \\
\hline & 116 & directing the meaning they take from a text & \multirow{2}{*}{ critiques lenses } \\
\hline Elisabeth & 117 & yeah & \\
\hline \multirow[t]{3}{*}{ Maya } & 118 & You know Doug said & \\
\hline & 119 & in however he introduced that book & \multirow{2}{*}{$\begin{array}{l}\text { Prince Cinders } \\
\text { while reading }\end{array}$} \\
\hline & 120 & I was listening to it from a feminist perspective & \\
\hline Elisabeth & 121 & yes & \\
\hline \multirow[t]{7}{*}{ Maya } & 122 & Maybe because it's like you said "Cinderella" & \\
\hline & 123 & But it kind of ruins the story & \multirow[t]{3}{*}{ the particular lens } \\
\hline & 124 & you know & \\
\hline & 125 & [pause] & \\
\hline & 126 & But I would like to have what you call & \multirow{3}{*}{$\begin{array}{l}\text { voice lowers } \\
\text { of literary theory }\end{array}$} \\
\hline & 127 & the tools and the language & \\
\hline & 128 & you know & \\
\hline Doug & 129 & what do you mean it ruins the story? & \multirow{7}{*}{$\begin{array}{l}\text { seeking clarification } \\
\text { while listening }\end{array}$} \\
\hline \multirow[t]{5}{*}{ Maya } & 130 & well the whole time I'm thinking & \\
\hline & 131 & like & \\
\hline & 132 & I'm trying to figure out & \\
\hline & 133 & from a feminist perspective & \\
\hline & 134 & what I should be offended by & \\
\hline All & 135 & [laugh] & \\
\hline
\end{tabular}

to interpreting the story (that is, examine our cultural norms on gender and how the writer appears to challenge them), and I implicitly raised a question about "literary lenses" as a metaphor for literary theories. After generating a "running record" of the class, I created a transcript of the interaction (presented in Table 6.1), which allowed Elisabeth and me to examine what occurred and design links for the next class meeting (February 20).

Elisabeth described the metaphor of lenses as a "heuristic device" and as "a little artificial" (Line 102), because it does not adequately portray how literary scholars apply theories; at this point in the developing interaction, she offers an alternative metaphor, "a kaleidoscope" (Line 108). One of the students, Maya, 
TABLE 6.2 Sequence of intertextually linked events: How readers fill "gaps" of literary texts

\begin{tabular}{|c|c|c|c|}
\hline January 30 & February 6 & February 13 & February 20 \\
\hline $\begin{array}{l}\text { Discussed Mellor, } \\
\text { Davies, and O'Neill } \\
\text { (2000): readers fill } \\
\text { gaps using } \\
\text { assumptions from } \\
\text { cultural experiences. }\end{array}$ & $\begin{array}{l}\text { Discussed a poem } \\
\text { and how readers } \\
\text { fill gaps based on } \\
\text { tone, background } \\
\text { experiences, etc. }\end{array}$ & $\begin{array}{l}\text { Discussed literary } \\
\text { theory and } \\
\text { metaphor of literary } \\
\text { "lenses"; example: } \\
\text { "feminist" reading } \\
\text { of Prince Cinders. }\end{array}$ & $\begin{array}{l}\text { Discussed interactional } \\
\text { sequence from Feb. 13: } \\
\text { Elisabeth's and Maya's } \\
\text { perspectives of lenses. }\end{array}$ \\
\hline
\end{tabular}

pointed to a statement made earlier in the class by guest speaker, Dr. Sheridan Blau: teachers should not make students dependent on teachers for interpretations. Maya followed Elisabeth's critique by implying the suggestion of using a particular "lens" directs students to a specific type of interpretation (Line 116). She recalled how I, moments before the reading of Prince Cinders, suggested interpreting the text from a feminist perspective. She implied my proposal diluted her interest in the story. Instead of preparing to experience the story, which she said children would enjoy on its own merit - regardless of their knowledge of Cinderella or gender norms, Maya said, "I'm trying to figure out/from a feminist perspective/what I should be offended by" (lines 132-134).

My analysis of the interaction, and subsequent conversations with Elisabeth, led us to show the transcript to students during the February 20 class session to reflect on Maya's position and assumptions, and what both revealed about her perspective of a feminist reading and her - and Elisabeth's - critique of "lens" as a metaphor. By constructing and (re)presenting transcripts, we demonstrated to students how classroom discourse offered opportunities for discussion and how the analysis influenced the design of the next class session and deepened our understandings of the role and limitations of a concept ("lens"). Furthermore, the analysis was part of a larger sequence of how readers fill gaps in literary texts based on their knowledge and experiences (see Table 6.2). In the next section, I describe a second example of how intertextually tied events led to the construction of a particular interpretative principle, shifting back to February 13.

\section{Constructing principles of literary interpretation for teaching}

\section{Example 2}

On February 13, guest speaker Sheridan Blau opened the class meeting with perspectives on teaching literary texts, including a critique of prereading activities. Denise, returning to her dilemma with her "unmotivated" students, asked him how to engage students in difficult texts (her example, Things Fall Apart by Chinua Achebe), particularly questioning him about the value of "prereading" activities to generate students' interest. Sheridan stated he eschews "prereading" 
activities; rather, he chooses texts for students to "interrogate," particularly so students can explore relevant topics, characters, or themes and become interested through the process (cf. Blau, 2003). Sheridan stated his main concern with "prereading" activities is teachers may prepare students in ways construed as "kind of fake" (that is, providing activities that do not engage students in ways experienced readers become engaged). For example, asking students to read about euthanasia before reading John Steinbeck's Of Mice and Men suggests an interpretation before students have had a chance to "interrogate" the text. Experienced readers would not typically read about euthanasia before entering the text, although the text may lead readers to inquire about the concept. Implicitly, therefore, Sheridan suggested teachers make visible to students practices of experienced readers.

On February 20, two significant, related interactions occurred. First, based on a comment during Sheridan's discussion, Elisabeth and I selected "The Story of an Hour" by Kate Chopin for students to read. Following the public reading, I raised a question about the value of literary discussions in classrooms, especially observing the many interpretations offered and the conundrum for teachers about what to do with them. As we describe in more detail in another study (Baker \& Däumer, 2015a), Elisabeth argued, the value is not in offering interpretations; rather, students must develop a "stake" in their interpretation. In the next event, one of the students, Annalise, led the class through a "reading event," selecting the poem "Shirts" by Robert Pinsky. She followed the pattern of previous reading events: read the text aloud, encourage responses, and lead a discussion of the text. However, she also provided students with history behind the allusions in the poem; therefore, according to Sheridan's principle, she made us dependent on her for interpretation. Upon analysis of the "running record," Elisabeth and I viewed this moment as a "rich point" for all of us, because Annalise's approach to the text, the class norm to that point, reflected what Sheridan cautioned against.

These two events and principles (encourage students to have a stake in their argument and create opportunities for students to become independent readers) led us to (re)design the next class meeting (March 5 - the class did not meet on February 27). However, most importantly, observations of these two events that led to the design of March 5 became obvious only after we examined transcripts and agreed on implications of what we had observed.

After analyzing transcripts of the two class meetings (February 13 and 20), and microanalyzing selected sequences, Elisabeth and I designed a two-poem activity for March 5. We agreed to each choose a poem and provide students with opportunities to read and interrogate the texts. We further agreed the discussion of each poem would include concepts discussed in recent class meetings: students developing a stake in their textual argument (Elisabeth's focus), teachers providing students with opportunities to engage as experienced readers, and readers consulting relevant material to guide interpretation as necessary (my focus).

On March 5, I briefly described to the class relevant events from the previous two class meetings, providing students with a handout showing conceptual links. 
Next, Elisabeth introduced the poem "St. Roach" by Muriel Rukeyser, and, as had been the pattern, she asked two students to each read the poem aloud, permitting time for all to peruse and interrogate the text. Elisabeth raised questions about what students needed as readers to develop a stake in their argument and support it with textual evidence. For the second poem, "In Jerusalem" by Mahmoud Darwish, I invited students to read the poem silently; then a student read it aloud, and I initiated a conversation about the text, including what aspects proved challenging and worthy of exploration, potentially through other texts (e.g., the poet's background experiences, allusions to place, etc.). I supplied a few texts students could choose to read.

An important outcome of the two events was a discussion about the potential value of teachers exploring texts as inquirers with students, instead of arriving to class as an expert on the text, one who prompts students toward predetermined answers or acceptable interpretations. Elisabeth briefly described the value of teachers and students becoming "inquirers and searchers" of textual interpretations and how teachers should avoid signaling to students that teachers have the answers. The intonation of her voice indicated an example teacher proposing to students to "become inquirers," suggesting teachers avoid expecting students to already know aspects of texts; rather, teachers should approach students as fellow inquirers: "Let's find out/and let's begin searching" for answers to our questions about a text.

Next, I responded by adopting the role of a teacher whose actions might annoy students, using a mocking tone of voice: "I know the text really well/and I know the answer to every question I ask/and I'm waiting to see if you've got it [the answer]." Elisabeth responded from a student perspective: "Why should I make the effort if you already know?” I concluded by linking Sheridan's perspective on the value of student-generated inquiry. The sequence, therefore, modeled the inquiry approach we encouraged, beginning with our analysis of classroom interactions and questions and modeling how we were in the process of constructing interpretative principles.

Figure 6.1 charts the described sequence to demonstrate intertextual links across class periods and represents the construction of an interpretative principle (guiding students to become independent readers). Beginning on February 13, Sheridan introduced the principle and Maya echoed it. Although the focus of class during February 20 was the potential value of literary theories, which was one reason we read and discussed "The Story of an Hour," Elisabeth's suggestion of a "stake" in an interpretation and Annalise's "rich point" led us to explore the sequence and link it to the principle of guiding students to become more independent as interpreters of texts.

\section{Discussion}

I have explored the value of incorporating an Interactional Ethnographic perspective to examining classroom interactions for purposes of teachers and students developing deeper understandings of literary interpretation by what is getting 
Dates of class periods

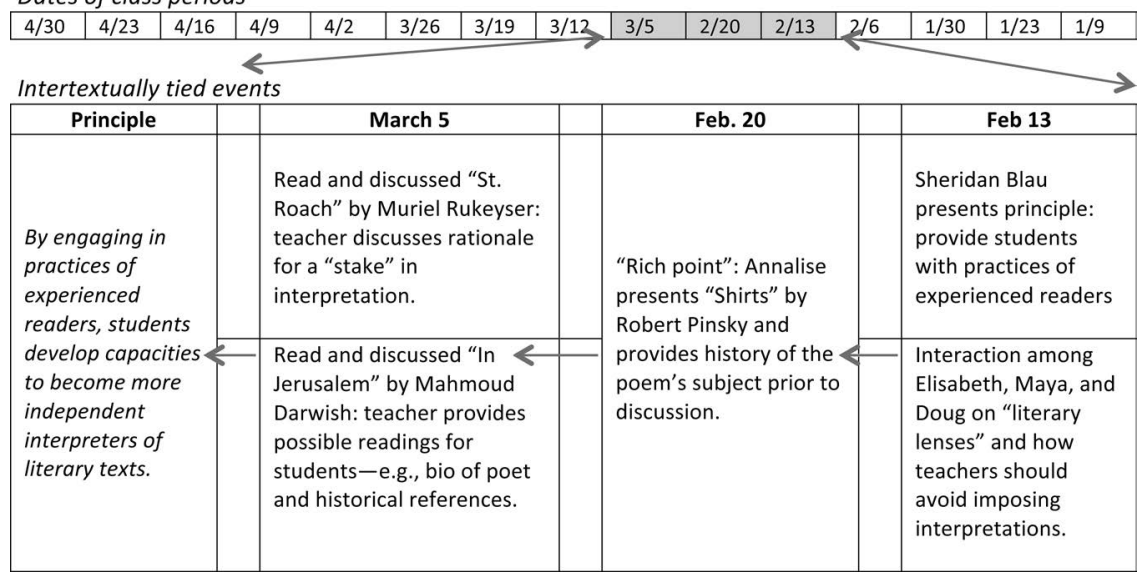

FIGURE 6.1 Constructing an interpretative principle.

accomplished through discursive actions. I unfolded how an inquiry approach and exploration of classroom discourse became a model for students, particularly as Elisabeth and I demonstrated links among (inter)disciplinary perspectives and conversations, students' experiences as readers and teachers of literary texts, and principles and practices constructed over time in the course. By adapting an Interactional Ethnographic perspective, we generated a metadiscourse and initiated multiple layers of analysis (e.g., "running records" and event maps) that led us to (re)design curriculum; and analysis of selected sequences led students and us to deeper understandings of selected phenomena.

By analyzing discursive interactions, we were able to better understand the interactions, which we may have missed during real-time exchanges. Although teachers cannot transcribe each session of a course, they may elect to record and transcribe selected sequences and use transcripts as a practice of the class, as we did. We used transcripts, for example, to show interactional sequences and how (re)examination of an event may lead to deeper understandings; I gave transcripts to individual students to observe how they described their research, or how others responded; and I demonstrated to students how to use transcripts to trace ideas and their developing understandings of particular phenomena.

For example, initially Denise described a conflict she faced as an instructor: her students appeared unmotivated, particularly displaying a lack of interest in reading the novel Things Fall Apart; yet, she described a list of needs that had led her to become a reader, needs she had not supplied to her students. On March 12 (following the sequenced described above, February 13-March 5), Denise described to the class her recent discoveries about her students and instructional approach, including shifting away from a deficit model perspective. Table 6.3 is a partial transcript of Denise demonstrating her deepening understanding of her students and of her role as the more experienced other. First, she recounted the students' 
TABLE 6.3 Denise reflects on the need for negotiation with students

\begin{tabular}{lll}
\hline Line & Discourse & Notes \\
\hline 201 & When you're inviting [students] to talk about something & \\
202 & you have to give them something they want to talk about & \\
203 & and usually it's about "why I don't like reading this book" & \\
204 & which essentially amounts to a lot of fear. & As an example is... \\
205 & A lot of what they say is & \\
206 & "I'm afraid" & \\
207 & "I'm afraid I don't know" & \\
208 & "I'm afraid I will sound stupid" & \\
209 & So this there's the curriculum negotiation \\
210 & there's the negotiation between the student and the teacher & \\
211 & that says "I'm not going to do this & \\
212 & until you tell me why \\
213 & and I know that you're going to help me" & \\
\hline
\end{tabular}

apparent lack of respect for authority and of her as an instructor; however, she said she had begun to realize she was expecting students to read a difficult text but was ignoring their needs as readers and as students. She recognized students needed her to address concerns, such as, "why I don't like reading this book" (line 203), and alleviate their fears, which she inferred from their questions and comments (cf. lines 206-213), and, most importantly, state how she would help them read difficult texts.

To further encourage Denise's (re)examination of her dilemma, I gave her the transcript of the 5-minute discussion, which became a resource for her final project, an essay describing her progress on encouraging students to read challenging texts. Denise had recognized the initial "rich point" and addressed it in the conclusion of the essay, including the need for her to select a different text for her students. (She also used transcripts from her class to exemplify observations.) The following excerpt demonstrates how she had enhanced her capacity to communicate the complexities of the apparent disconnect and how she planned to resolve it, including selecting a different text.

First, I expected students to engage in discussions at the beginning of the year before students knew or trusted me, or their peers. Classroom community was not formed yet,... Furthermore, I did not give explicit instruction about how to engage in authentic discussion or the value of doing so. My expectations were not clear .... I also learned from the students that they need a book with characters their age and facing similar, age-appropriate conflicts. The exposure to world literature requires that students can easily see themselves in the characters, which was not so with Things Fall Apart.

Furthermore, Denise, as Elisabeth and I had encouraged students to recognize, implies she had learned when exploring teacher/student interactions in 
classrooms, that interactions are "a continuing, cumulative experience for the participants,... [who] draw on their shared history all the time when they communicate," and we must examine interactions over time if we want to "do justice to what teachers and learners achieve, or fail to achieve, every working day" (Mercer, 2010, p. 10).

\section{References}

Agar, M. (1994). Language shock: Understanding the culture of conversation. New York: William Morrow.

Anderson-Levitt, K. M. (2006). Ethnography. In G. Camilli, P. Elmore, \& J. Green, (Eds.) Handbook of complementary methods in education research (3rd ed., pp. 279-295). Washington, DC: American Educational Research Association.

Appleman, D. (2009). Critical encounters in high school English: Teaching literary theory to adolescents. Urbana, IL: NCTE.

Baker, W. D. (2001). Artists in the making: An ethnographic investigation of discourse and literate practices as disciplinary processes in a high school advanced placement studio art classroom (Unpublished doctoral dissertation). University of California, Santa Barbara.

Baker, W. D., \& Däumer, E. (2015a). Designing interdisciplinary instruction: Exploring disciplinary and conceptual differences as a resource. Pedagogies: An International Journal, 10(1), 38-53.

Baker, W. D., \& Däumer, E. (2015b). Understanding understanding: Implications of interdisciplinary articulation for instruction and assessment. Language Arts Journal of Michigan, 31(1), 28-38.

Baker,W. D., \& Green, J. L. (2007). Limits to certainty in interpreting video data: Interactional ethnography and disciplinary knowledge. Pedagogies: An International Journal, 2(3), 191-204.

Baker, W. D., Green, J. L., \& Skukauskaite, A. (2008). Video-enabled ethnographic research: A mircroethnographic perspective. In G. Walford (Ed.), How to do educational ethnography (pp. 77-114). London, England:Tufnell.

Blau, S. (2003). The literature workshop. Portsmouth, NH: Heinemann.

Blau, S. (2014). Literary competence and the experience of literature. Style, 48(1), 42-47.

Bloome, D., Carter, S. C., Christian, B. M., Otto, S., \& Shuart-Faris, N. (2005). Discourse anal$y$ sis and the study of classroom language and literacy events. New York: Routledge.

Bloome, D., Castanheira, M. L., Leung, C., \& Rowsell, J. (2018). Re-theorizing literacy practices: Complex social and cultural contexts. New York: Routledge.

Carney, M., \& Indrisano, R. (2013). Disciplinary literacy and pedagogical content knowledge. The Journal of Education, 193(3), 39-49.

Castanheira, M. L., Crawford, T., Dixon, C. N., \& Green, J. L. (2001). Interactional ethnography: An approach to studying the social construction of literate practices. Linguistics and Education, 11(4), 353-400.

Edwards, D., \& Mercer, N. (1987). Common knowledge: The development of understanding in the classroom. London, England: Methuen.

Francis, J. (2008). Aesthetic confusion: The legacy of new criticism. Language Arts Journal of Michigan, 24(1), 28-33.

Gee, J. P., \& Green, J. L. (1998). Discourse analysis, learning, and social practice: A methodological study. Review of Research in Education, 23, 119-169.

Green, J. L., \& Bloome, D. (1997). Ethnography and ethnographers of and in education: A situated perspective. In S. B. Heath, J. Flood, \& D. Lapp (Eds.), Handbook for research in the communicative and visual arts (pp. 181-202). New York: Macmillan. 
Green, J., \& Meyer, L. (1991). The embeddedness of reading in classroom life: Reading as a situated process. In C. D. Baker \& A. Luke (Eds.), Towards a critical sociology of reading pedagogy (pp. 141-160). Philadelphia, PA: John Benjamins.

Green, J. L., Skukauskaite, A., \& Baker, W. D. (2012). Ethnography as epistemology: An introduction to educational ethnography. In J. Arthur, M. Waring, R. Coe, \& L.V. Hedges (Eds.), Research methodologies and methods in education (pp. 309-321). London, England: SAGE.

Gumperz J. J. (1997). Communicative competence. In N. Coupland \& A. Jaworski (Eds.), Sociolinguistics (pp. 39-48). London, England: Palgrave.

Hunt, C.S. (2018). Toward dialogic professional learning: Negotiating authoritative discourses within literacy coaching interaction. Research in the Teaching of English, 52(3), 262-287.

Hyland, K. (2017). Metadiscourse: What is it and where is it going. Journal of Pragmatics, 113, 16-29.

Hymes, D. H. (1972). On communicative competence. In J. B. Pride, \& J. Holmes (Eds.), Sociolinguistics (pp. 269-293). Baltimore, MD: Penguin.

Kelly, G. J., Luke, A., \& Green, J. (2008). What counts as knowledge in educational settings: Disciplinary knowledge, assessment, and curriculum. Review of Research in Education, 32, vii-x.

Marshall, J., \& Smith, J. (1997). Teaching as we're taught: The university's role in the education of English teachers. English Education, 29(4), 246-268.

McCann, T. M. (2014). Transforming talk into text: Argument writing, inquiry, and discussion, Grades 6-12. New York: Teachers College Press.

Mellor, B., Patterson, A., \& O'Neill, M. (2000). Reading fictions: Applying literary theory to short stories. Urbana, IL: NCTE.

Mercer, N. (2010). The analysis of classroom talk: Methods and methodologies. British Journal of Educational Psychology, 80, 1-14.

Olsen, A. W. (2018). How language defines 'learning': A classroom view. Acta Paedagogica Vilnensia, 41, 58-71.

Rex, L., \& Green, J. (2008). Classroom discourse and interaction: Reading across the traditions. In B. Spolsky, \& F. M. Hult (Eds.), The handbook of educational linguistics (pp. 571-584). Hoboken, NJ: Blackwell.

Rex, L. A., \& Schiller, L. (2009). Using discourse analysis to improve classroom interaction. New York: Routledge.

Street, B. (2016). Learning to read from a social practice view: Ethnography, schooling and adult learning. Prospects, 46, 335-344.

Tang, K-S. (2017). Analyzing teachers' use of metadiscourse: The missing element in classroom discourse analysis. Science Education, 101(4), 548-583.

Vetter, A., Schieble, M., \& Meacham, M. (2018). Critical conversations in English education: Discursive strategies for examining how teacher and student identities shape classroom discourse. English Education, 50(3), 255-282.

Wilson, B. (2014). Teach the how: Critical lenses and critical theory. English Journal, 103(4), 68-75. 
$\Longrightarrow$ Taylor \& Francis Taylor \& Francis Group http://taylorandfrancis.com 